\title{
Photoperiodic history and a changing melatonin pattern can determine the neuroendocrine response of the ewe to daylength
}

\author{
J. E. Robinson* and F. J. Karsch \\ Reproductive Endocrinology Program and Department of Physiology, The University of Michigan, \\ Ann Arbor, Michigan 48109, U.S.A.
}

\begin{abstract}
Summary. The reproductive neuroendocrine response of Suffolk ewes to the direction of daylength change was determined in animals which were ovariectomized and treated with constant release capsules of oestradiol. Two groups of animals were initially exposed to 16 or $10 \mathrm{~h} \mathrm{light/day} \mathrm{for} 74$ days. On day zero of the study, when one group of ewes was reproductively stimulated (elevated LH concentrations) and the other reproductively inhibited (undetectable LH concentrations), half the animals from each group were transferred to an intermediate daylength of $13 \mathrm{~h} \mathrm{light/day.} \mathrm{The} \mathrm{remaining}$ ewes were maintained on their respective solstice photoperiods to control for photorefractoriness. $\mathrm{LH}$ concentrations rose in animals experiencing a $3 \mathrm{~h}$ decrease in daylength from $16 \mathrm{~L}: 8 \mathrm{D}$ to $13 \mathrm{~L}: 11 \mathrm{D}$ while $\mathrm{LH}$ concentrations fell to undetectable values in those that experienced a $3 \mathrm{~h}$ increase in daylength from $10 \mathrm{~L}: 14 \mathrm{D}$ to $13 \mathrm{~L}: 11 \mathrm{D}$. The photoperiodic response of the Suffolk ewe, therefore, depends on her daylength history. Such a result could be explained if the 24 -h secretory pattern of melatonin secretion, known to transduce photoperiodic information to the reproductive axis, was influenced by the direction of change of daylength. Hourly samples for melatonin were collected for $24 \mathrm{~h} 17$ days before and three times after transfer to 13L:11D. The melatonin secretory profile always conformed to daylength. Therefore, the mechanism by which the same photoperiod can produce opposite neuroendocrine responses must lie downstream from the pineal gland in the processing of the melatonin signal.
\end{abstract}

\section{Introduction}

Daylength has been demonstrated to be an important cue for timing the period of reproductive activity of sheep as well as many other seasonally breeding species (Yeates, 1949; Hafez, 1952; Mauleon \& Rougeot, 1962; Reiter \& Follett, 1980). Typically, breeding begins in autumn, as daylength is decreasing and ends in late winter as the photoperiod is increasing. Sheep are, therefore, considered to be 'short-day breeders'. This is substantiated by laboratory studies which indicate that short days can be stimulatory and long days suppressive to reproduction (Yeates, 1949; Legan \& Karsch, 1980).

Experiments in other seasonal breeders have led to the concept of a species specific "critical daylength', a pivotal photoperiod on either side of which lies reproductive induction or inhibition (Elliott, 1976). In their outdoor environment, however, sheep may not use an absolute critical daylength to time reproductive transitions. Under natural conditions, the same daylength occurs twice per year; hence breeding might be expected to extend symmetrically about the solstices. This,

\footnotetext{
*Present address: AFRC Institute of Animal Physiology and Genetics Research, Babraham, Cambridge CB2 4AT,
} U.K. 
however, is generally not the case. Most breeds of sheep are reproductively stimulated at one time of year but inhibited under the same photoperiod at the other (Hafez, 1952; Robinson \& Karsch, 1984). Therefore, the concept of an absolute critical daylength may be untenable. Rather, as is the case in other seasonal breeders such as the Japanese quail, the wild European rabbit and certain rodents, the photoperiodic history, and therefore the direction of change of daylength, may be crucial in determining the reproductive state (Robinson \& Follett, 1982; Horton, 1984; Stetson, 1985; Boyd, 1986; Hoffmann et al., 1986).

In the present study, we sought to determine whether the reproductive response of the ewe to a given daylength depends upon her recent photoperiodic experience. Further, we examined whether the 24-h pattern of melatonin secretion is influenced by the direction of change in daylength. In this regard, melatonin is known to relay photoperiodic information to the reproductive axis of the ewe by virtue of being secreted only during the night (Lincoln \& Short, 1980; Karsch et al., 1984). Any discordant pattern of melatonin secretion, therefore, could constitute a mechanism whereby the same absolute daylength leads to different reproductive responses.

\section{Materials and Methods}

Animals and treatments. Experiments were conducted on 21 sexually mature Suffolk ewes maintained on a diet of hay. Before the study, animals were ovariectomized and treated with a subcutaneous Silastic capsule containing $3 \mathrm{~cm}$ of packed oestradiol-17 $\beta$ (Karsch et al., 1973). This treatment has been shown to maintain a physiological serum concentration of oestradiol (3-5 pg/ml: Legan et al., 1977; Karsch et al., 1980). Reproductive neuroendocrine responses were assessed from serum concentrations of $\mathbf{L H}$ in samples obtained twice a week by jugular venepuncture. Under stimulatory short daylengths, oestradiol has only a weak negative feedback action and LH concentrations are elevated; under inhibitory long daylengths oestradiol is a potent inhibitor of $\mathrm{LH}$ secretion and concentrations are low or undetectable (Legan et al., 1977; Legan \& Karsch, 1980). It is now well established that this change in response to oestradiol negative feedback constitutes the endocrine basis for seasonal fluctuations in ovarian function and that sustained rises and falls in LH in this animal model parallel seasonal changes in oestrous cyclicity (Karsch et al., 1984). Specifically sustained increases in $\mathrm{LH}$ above $\mathrm{I} \mathrm{ng} / \mathrm{ml}$ occur at the same time as the onset of oestrous cycles; decreases in $\mathrm{LH}$ below $1 \mathrm{ng} / \mathrm{ml}$ are coincident with the onset of anoestrus (Robinson \& Karsch, 1984; Robinson et al., 1985 ; F. J. Karsch, unpublished).

Photoperiodic manipulations. Animals were housed in light-sealed rooms in which daylength was regulated automatically. Light was provided by fluorescent tubes which produced an intensity of 350 lux lateral to the sheep's head. A dim red light ( $<2$ lux) remained on continuously to facilitate night-time blood collection. The experiment consisted of a 10-month priming period and a 3-month experimental period (Fig. 1). At the start of the priming period, all ewes were reproductively suppressed (mean LH concentrations undetectable). During this priming phase ewes were assigned to one of two groups. The first $(\mathrm{N}=12$ ) was to be reproductively suppressed at the start of the experimental period on a daylength similar to that of the summer solstice at Ann Arbor, Michigan $\left(42^{\circ} \mathrm{N}\right)$ and was treated as follows: $8 \mathrm{~L}: 16 \mathrm{D}$ for 80 days, $16 \mathrm{~L}: 8 \mathrm{D}$ for 60 days, $8 \mathrm{~L}: 16 \mathrm{D}$ for 70 days, $16 \mathrm{~L}: 8 \mathrm{D}$ for 74 days. The other group $(\mathrm{N}=9)$ was to be reproductively stimulated at the start on a daylength similar to that of the winter solstice and was treated as follows: $8 \mathrm{~L}: 16 \mathrm{D}$ for 100 days, 16L:8D for 110 days, $10 \mathrm{~L}: 14 \mathrm{D}$ for 74 days. Such manipulations also ensured that at the start of the experimental period all ewes were photosensitive.

The experiment began on 12 April 1984 when 6 ewes were given an abrupt 3-h decrease in photoperiod (16L:8D to 13L:11D). Simultaneously, 4 ewes experienced a $3-\mathrm{h}$ increase in daylength to the same intermediate photoperiod (10L:14D to 13L:11D). Daylength changes were made by altering the time of lights off (lights on in all photoperiods at $06: 00 \mathrm{~h}$ EST). The remaining ewes were maintained on their respective solstice photoperiods to control for photorefractoriness, spontaneous changes in reproductive condition which occur during extended periods of stimulatory or inhibitory photoperiods (Robinson \& Karsch, 1984; Robinson et al., 1985; Karsch et al., 1986). The 24-h secretory profile of melatonin was assessed before and three times after these photoperiodic shifts (Days -17 and $+7,41,81$; see M, Fig. 1). Samples were taken hourly; those at the light/dark transitions were collected within 15 min of lights on or off.

Assays. LH was assayed in duplicate in 25-200 $\mu \mathrm{l}$ samples of serum according to the method of Niswender et al. (1969) modified as described by Hauger et al. (1977). Sensitivity averaged $0.6 \mathrm{ng} / \mathrm{ml}$ for $200 \mu 1$ serum. Inter- and intra-assay coefficients of variation (CV) for three serum pools determined 6 times in each assay were $9 \cdot 3 \%$ and $6 \cdot 5 \%$, respectively ( 7 asssys). Melatonin concentrations were determined in duplicate in extracts of $500 \mu \mathrm{l}$ serum as described by Rollag \& Niswender (1976) with slight modifications (Bittman et al., 1983). Sensitivity averaged $2.5 \mathrm{pg} / \mathrm{ml}$. Values for a daytime serum pool measured 6 times in each assay averaged $56 \pm 4 \mathrm{pg} / \mathrm{ml}$; those for a night-time pool averaged $414 \pm 13 \mathrm{pg} / \mathrm{ml}$. Inter-assay CV for daytime and night-time serum pools averaged $29.8 \%$ and $13 \cdot 4 \%$, respectively.

Statistics. Data were analysed by comparing the proportion of ewes which responded with a rise or fall in LH by a specified time with that in the respective refractoriness control group. For this purpose, Fisher's exact probability test was used for animals initially maintained on 16L:8D; the Mann-Whitney two-sample rank-sum test was used for animals initially maintained on 10L:14D. 


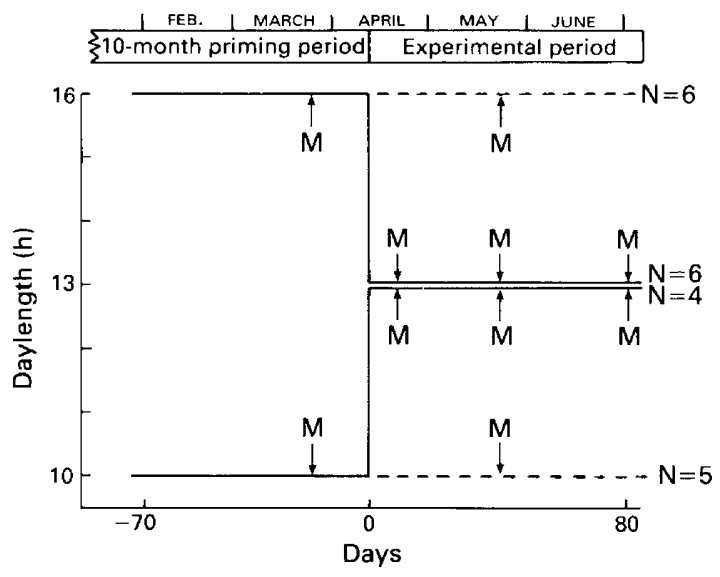

Fig. 1. Experimental design: daylengths to which 21 ovariectomized and oestradiol-treated ewes were exposed just before and during the 85-day experimental period (see text for details). $\mathrm{M}$ indicates the times of the 24-h sampling periods for melatonin. $\mathbf{N}=$ number of animals per group.

\section{Results}

Thirteen hours of light per day was regarded as stimulatory to reproductive neuroendocrine function in animals experiencing a $3-\mathrm{h}$ decrease in daylength (from $16 \mathrm{~L}: 8 \mathrm{D}$ to $13 \mathrm{~L}: 11 \mathrm{D}$; Fig. 2, left). About 40 days after this light shift, serum $\mathrm{LH}$ concentrations rose from $<0.6 \mathrm{ng} / \mathrm{ml}$ to $\sim 3.0 \mathrm{ng} / \mathrm{ml}$. These LH responses were significantly different $(P<0.01$, Fisher's exact test $)$ from those in the refractoriness controls maintained on $16 \mathrm{~L}: 8 \mathrm{D}$, in which $\mathrm{LH}$ values remained undetectable. The maximal concentration of LH achieved in animals exposed to the 3-h decrease in photoperiod, however, was less than the values we have observed in ewes which experienced a larger decrement in daylength (see Fig. 2, LH values above $10 \mathrm{ng} / \mathrm{ml}$ on Day 0 in ewes exposed to 10L:14D). The 3-h reduction in daylength to $13 \mathrm{~L}: 11 \mathrm{D}$ may therefore represent a marginally stimulatory photoperiod (see 'Discussion').

In marked contrast to the reproductive response following the shift from 16 to $13 \mathrm{~h} \mathrm{light/day,}$ 13L:I1D was regarded as inhibitory to reproductive neuroendocrine function by animals experiencing a 3-h increase in daylength from 10L:14D (Fig. 2, right). LH concentrations plunged from above $10 \mathrm{ng} / \mathrm{ml}$ and became undetectable while values remained maximal in refractoriness controls maintained on 10L:14D. Although LH concentrations subsequently fell as these controls became refractory to the stimulatory daylength, the fall occurred significantly later $(P<0 \cdot 005$, MannWhitney two-sample rank-sum test) than in experimental ewes. At the time $\mathrm{LH}$ in this control group became undetectable, animals had actually experienced 10L:14D for 142 days (74 pretreatment days plus 68 experimental days). This duration of exposure to an inductive photoperiod is similar to that which we have observed in several other studies (Malpaux et al., 1985; Karsch et al., 1986).

The 24-h patterns of circulating melatonin 17 days before transfer from the solstice photoperiods and after 7 days of 13L:1 ID are shown in Fig. 3. Without exception, the melatonin secretory profiles conformed to photoperiod, i.e. hormone concentrations were low during the light phase and elevated during darkness, and the period of increased melatonin secretion spanned the dark phase. Patterns determined after 41 and 81 days of 13L:11D (not shown) were essentially the same and melatonin release reflected daylength irrespective of photoperiodic history and the neuroendocrine state of the animals. 


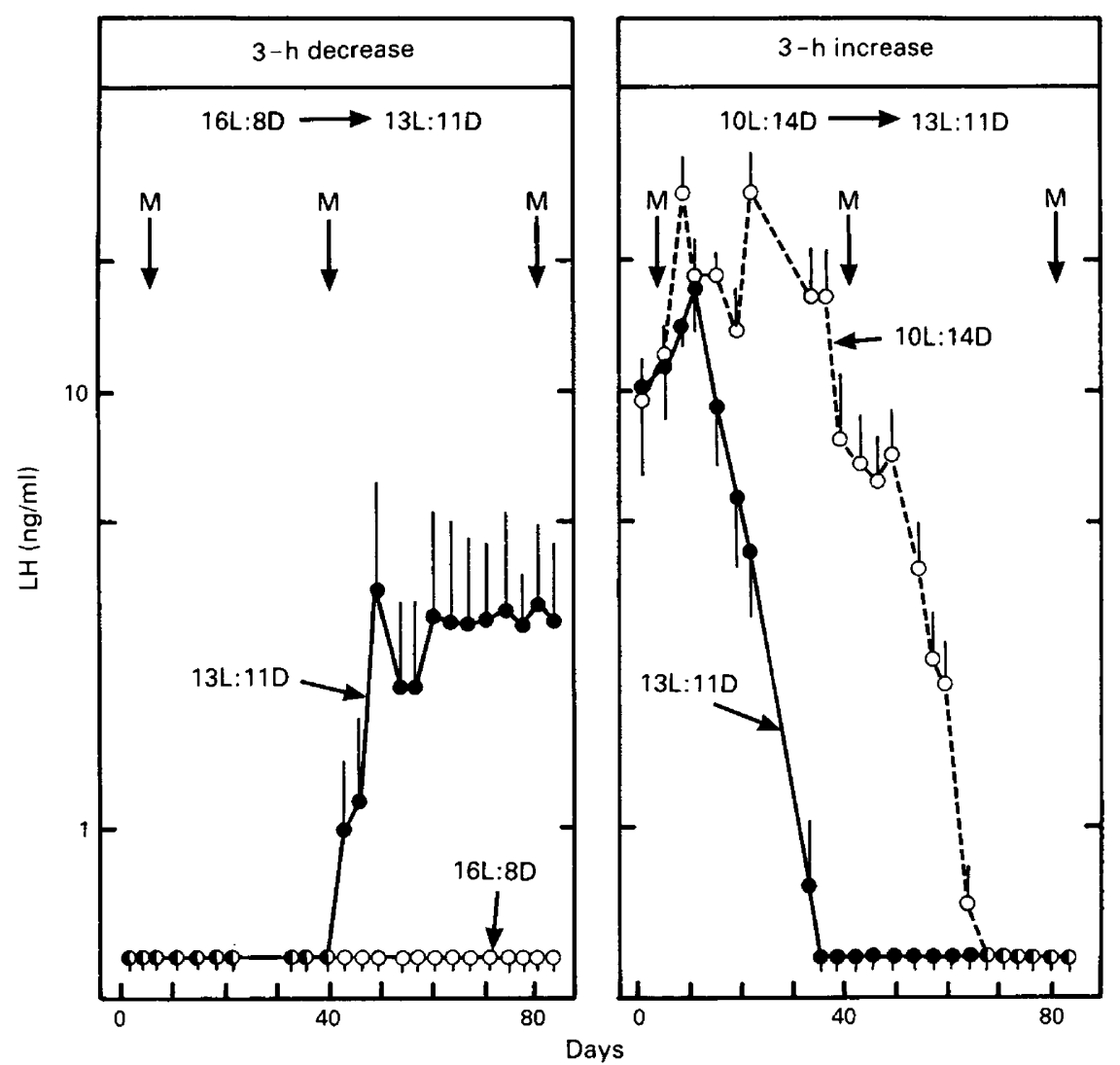

Fig. 2. Serum LH concentrations (mean \pm s.e.m.) in ewes which experienced a 3-h decrease in daylength from 16L:8D to 13L:11D (solid symbols, left), or a 3-h increase in daylength from 10L:14D to 13L:11D (solid symbols, right). Controls for refractoriness remained on the solstice photoperiods of 16L:8D (open symbols, left) or 10L:14D (open symbols, right). $\mathrm{M}$ indicates the time of blood sampling for melatonin measurements.

\section{Discussion}

Our findings demonstrate that the reproductive neuroendocrine response of the Suffolk ewe to daylength depends on her photoperiodic experience. Further, they indicate that this species does not exhibit a rigid critical daylength for reproductive induction or inhibition, and raise the possibility that the ewe may be sensitive to the direction of photoperiodic change and alterations in the secretory pattern of melatonin. That photoperiodic history may be of widespread importance in seasonal reproduction is suggested by observations on Japanese quail, juvenile microtine voles, adult and juvenile Djungarian hamsters and rabbits (Robinson \& Follett, 1982; Hoffmann, 1984; Horton, 1984; Stetson, 1985; Boyd, 1986; Hoffmann et al., 1986).

The amplitude of the LH rise following the 3-h decrease in daylength was not as large as that which we had observed in ewes experiencing larger decrements in daylength (priming phase of the study; Legan \& Karsch, 1980; Bittman et al., 1983; Karsch et al., 1986). This supports the previous conclusion that the magnitude of the reproductive neuroendocrine response of the ewe depends upon the strength of the photoperiodic signal (Robinson et al., 1985) and that the 3-h reduction in daylength constituted a marginally stimulatory signal. It is not possible from the present study to assess whether the photoperiodic signal would have been sufficient to promote the onset of oestrous cycles had the ewes not been ovariectomized. However, under the natural and artificial 


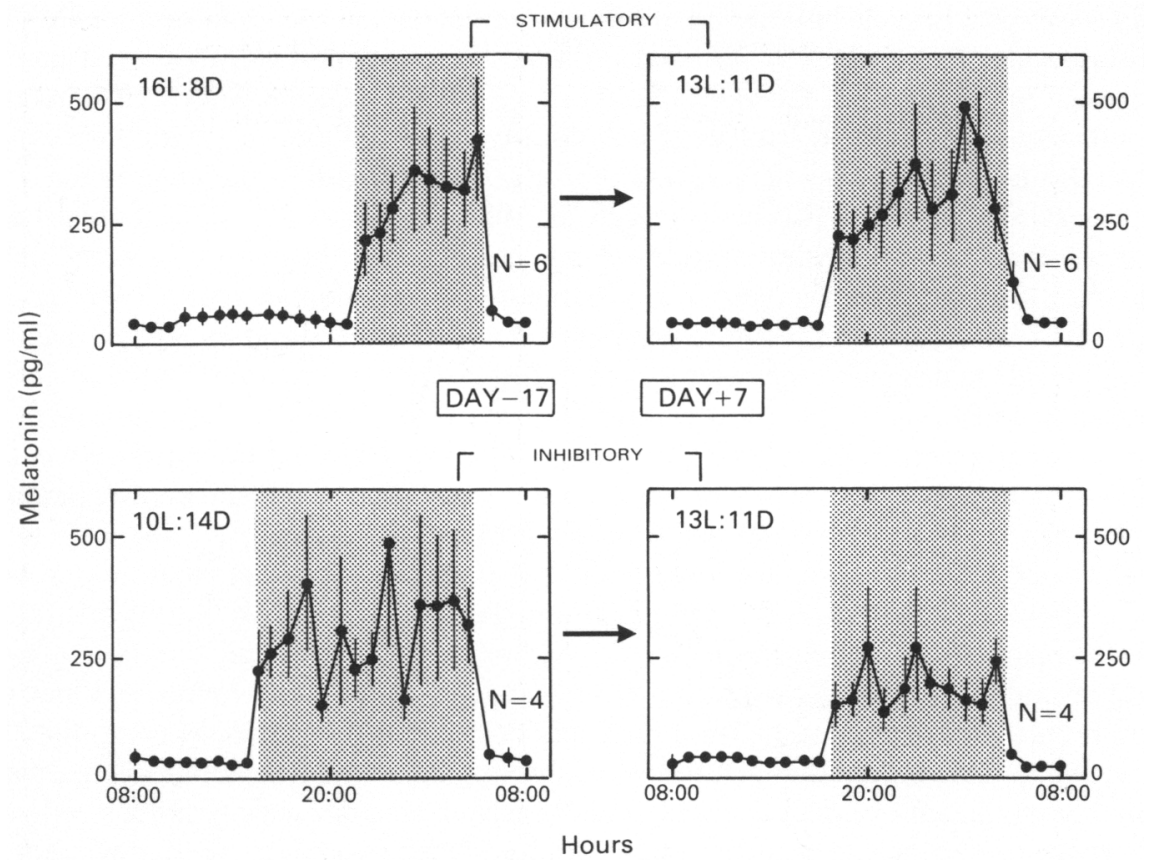

Fig. 3. Diurnal patterns of serum melatonin concentrations (mean \pm s.e.m.) in ovariectomized-oestradiol-treated ewes determined 17 days before transfer from the solstice daylengths (left panels), or 7 days after being placed on 13L:11D (right panels). Shaded areas depict the period of darkness. $\mathrm{N}=$ number of animals.

photoperiod conditions, there is a strong temporal association between the onset of oestrous cycles in ovary-intact ewes and $\mathrm{LH}$ concentrations above $1 \mathrm{ng} / \mathrm{ml}$ in ovariectomized-oestradiol-treated animals. In this study $\mathrm{LH}$ concentrations rose to an average of $3 \mathrm{ng} / \mathrm{ml}$.

Although the importance of photoperiodic history has been most thoroughly studied in the Japanese quail (Robinson \& Follett, 1982) it has not proved possible to unravel the underlying mechanism in this species. This is, in part, because the photoneuroendocrine pathway in birds is not well understood. The sheep provides a good opportunity to begin to explore the underlying mechanism because the pineal gland and its light-regulated secretion of melatonin are known to be important components of the pathway, and secretory profiles of melatonin can easily be determined in individual animals. Thus, the generation of a melatonin profile which does not accurately reflect photoperiod could constitute a mechanism whereby the same photoperiod leads to opposite reproductive responses in photosensitive animals.

In the present study, however, the melatonin secretory pattern always conformed to daylength. Therefore, the mechanism whereby the same photoperiod can stimulate or inhibit LH secretion in ovariectomized oestradiol-treated ewes must lie downstream from the pineal gland, possibly in the processing of the melatonin signal. In this regard, two hypotheses may be forwarded: either the processing of the melatonin signal depends on the reproductive neuroendocrine state of the animals, or the response to this signal depends upon the preceding melatonin pattern. The latter possibility is particularly attractive because, under different conditions, the response of ewes to melatonin is influenced by prior exposure to this hormone (Karsch et al., 1986).

The melatonin profiles in our study also have important implications concerning the critical feature of the melatonin pattern which carries photic information. At present there are two main conceptual models to explain how melatonin transduces daylength information in a photoperiodic species, one involving duration and the other phase of elevated melatonin secretion (Goldman $e t$ al., 1982). According to the duration model, the length of the night dictates the length of time that 
melatonin is elevated in each $24-\mathrm{h}$ period and this provides the neuroendocrine code for daylength. In sheep this model is supported by observations that the duration of elevated melatonin secretion is proportional to the length of the night (Rollag et al., 1978; Lincoln \& Short, 1980; Arendt et al., 1981; Kennaway et al., 1983; Karsch et al., 1985). Moreover, studies involving infusion of melatonin into pinealectomized ewes suggest that reproductive state can be dictated by the period that melatonin is raised each $24 \mathrm{~h}$ (Bittman \& Karsch, 1984; Yellon et al., 1985). Similarly, infusion studies of the Djungarian hamster provide strong evidence that duration of nightly melatonin is critical in that long-day breeder (Carter \& Goldman, 1983; Goldman et al., 1984). Despite this supporting evidence, our present finding that the same absolute duration of the melatonin rise provoked opposite neuroendocrine responses in the ewe cannot be accommodated by the duration hypothesis in its most rigid form. Should duration prove to be pivotal in determining the breeding condition of the ewe, then it must be the duration relative to the preceding melatonin pattern, and therefore whether the period of secretion each night is expanding or contracting. A recent study of the male Djungarian hamster has also led to this conclusion (Hoffman et al., 1986).

The phase model is based on the hypothesis that there is a circadian rhythm of sensitivity to melatonin; the phase relationship of the melatonin rise to this sensitive period then dictates the reproductive response (Goldman et al., 1982). Although this hypothesis has not been formally tested in sheep, supporting evidence has been obtained from experiments involving timed injections of melatonin into pinealectomized Syrian hamsters (Watson-Whitmyre \& Stetson, 1983; WatsonWhitmyre, 1985). Our finding that a common melatonin pattern induces opposite neuroendocrine states could be explained by a phase model, if photoperiodic history were to influence the circadian time of the entrained melatonin sensitive phase. Although this remains to be studied, photoperiodic history is known to affect circadian rhythms in rodents under free-running conditions (Pittendrigh \& Daan, 1976).

In summary, our findings demonstrate that the concept of an absolute critical day length for reproductive stimulation or inhibition in the Suffolk ewe is untenable; the photoperiodic threshold and the response to melatonin vary with recent photoperiodic experience. The adaptive significance of the resulting seasonal shift in the photoperiodic threshold in the ewe may be to permit this 'short day' breeder to become sexually active under the relatively long (but decreasing) daylengths of late summer. Births would therefore occur in early spring, enabling growing lambs to benefit from a maximal period of favourable environmental conditions. Furthermore, breeding would be curtailed by the relatively short (but increasing) daylengths of late winter, preventing births at times when lambs could not attain sufficient body weight to survive their first winter.

We thank Mr Douglas Doop and Ms Barbara Glover for help with the experiments and radioimmunoassays; the Standards and Reagents Core Facility for preparation of the reagents; $\mathrm{Dr}$ G. D. Niswender, Dr M. D. Rollag and Dr L. E. Reichert, Jr for supplying assay reagents; Dr Morton Brown for statistical advice; and Mr Rob Jopling for drawing the illustrations. The work was supported by NIH-HD-11311 \& HD-18258.

\section{References}

Arendt, J., Symons, A.M. \& Laud, C. (1981) Pineal function in the sheep: evidence for a possible mechanism mediating seasonal reproductive activity. Experientia 37, 584-586.

Bittman, E.L. \& Karsch, F.J. (1984) Nightly duration of pineal melatonin secretion determines the reproductive response to inhibitory daylength in the ewe. Biol. Reprod. 30, 585-593.

Bittman, E.L., Dempsey, R.J. \& Karsch, F.J. (1983) Pineal melatonin secretion drives the reproductive response to daylength in the ewe. Endocrinology 113 , 2276-2283.
Boyd, I.L. (1986) Photoperiodic regulation of seasonal testicular regression in the wild European rabbit (Oryctolagus cuniculus). J. Reprod. Fert. 77, 463-470.

Carter, D.S. \& Goldman, B.D. (1983) Antigonadal effects of timed melatonin infusions in pinealectomized male Djungarian hamsters (Phodopus sungorus sungorus): duration is the critical parameter. Endocrinology 113, 1261-1267.

Elliott, J.A. (1976) Circadian rhythms and photoperiodic time measurement in mammals. Fedn Proc. Fedn Am. Socs exp. Biol. 35, 2339-2346.

Goldman, B.D., Carter, D.S., Hall, V.D., Roychoudhury, 
P. \& Yellon, S.M. (1982) Physiology of pineal melatonin in three hamster species. In Melatonin Rhythm Generating System, pp. 210-231. Ed. D. C. Klein. S. Karger, Basel.

Goldman, B.D., Darrow, J.M. \& Yogev, L. (1984) Effects of timed melatonin infusions on reproductive development in the male Djungarian hamster (Phodopus sungorus). Endocrinology 114, 2074-2083.

Hafez, E.S.E. (1952) Studies of the breeding season and reproduction of the ewe. J. agric. Sci., Camb. 42, 189-265.

Hauger, R.L., Karsch, F.J. \& Foster, D.L. (1977) A new concept for control of the estrous cycle of the ewe based on the temporal relationships between luteinizing hormone, estradiol and progesterone in peripheral serum and evidence that progesterone inhibits tonic LH secretion. Endocrinology 101, 807-817.

Hoffmann, K. (1984) Photoperiodic reaction in the Djungarian hamster is influenced by previous light history. Biol. Reprod. 30, Suppl. 1, Abstr. 50.

Hoffmann, K., Illnerova, H. \& Vanecek, J. (1986) Change in duration of the nighttime melatonin peak may be a signal driving photoperiodic responses in the Djungarian hamster (Phodopus sungorus). Neurosci. Lett. 67, 68-72.

Horton, T.H. (1984) Growth and reproductive development of male Microtus montanus is affected by the prenatal photoperiod. Biol. Reprod. 31, 499-504.

Karsch, F.J., Dierschke, D.J., Weick, R.F., Yamaji, T., Hotchkiss, J. \& Knobil, E. (1973) Positive and negative feedback control by estrogen of luteinizing hormone secretion in the rhesus monkey. Endocrinology 92, 799-804.

Karsch, F.J., Legan, S.J., Ryan, K.D. \& Foster, D.L. (1980) Importance of estradiol and progesterone in regulating $\mathbf{L H}$ secretion and estrous behavior during the sheep estrous cycle. Biol Reprod. 23, $404-413$.

Karsch, F.J., Bittman, E.L., Foster, D.L., Goodman, R.L., Legan, S.J. \& Robinson, J.E. (1984) Neuroendocrine basis of seasonal reproduction. Recent Prog. Horm. Res. 40, 185-232.

Karsch, F.J., Wayne, N.L. \& Bittman, E.L. (1985) Importance of duration of the nocturnal increase in melatonin secretion in determining the reproductive response to photoperiod. Proc. 7 th Int. Congr. Endocrinology, Quebec, pp. 139-142.

Karsch, F.J., Bittman, E.L., Robinson, J.E., Yellon, S.M., Wayne, N.L., Olster, D.H. \& Kaynard, A.H. (1986) Melatonin and photorefractoriness: loss of response to the melatonin signal leads to seasonal reproductive transitions in the ewe. Biol. Reprod. 34, 265-274.

Kennaway, D.J., Sanford, L.M., Godfrey, B. \& Friesen, H.G. (1983) Patterns of progesterone, melatonin and prolactin secretion in ewes maintained in four different photoperiods. J. Endocr. 45, 317-328.

Legan, S.J. \& Karsch, F.J. (1980) Photoperiodic control of seasonal breeding in ewes: modulation of the negative feedback action of estradiol. Biol. Reprod. 23, 1061-1068.

Legan, S.J., Karsch, F.J. \& Foster, D.L. (1977) The endocrine control of seasonal reproductive function in the ewe: a marked change in response to the negative feedback action of estradiol on luteinizing hormone secretion. Endocrinology 101, 818-824.
Lincoln, G.A. \& Short, R.V. (1980) Seasonal breeding: Nature's contraceptive. Recent Prog. Horm. Res. 36, $1-52$.

Mauleon, P. \& Rougeot, J. (1962) Regulation des saisons sexuelles chez des brebis de races differentes au moyen de divers rhythmes lumineux. Annls Biol. anim. Biochim. Biophys. 2, 209-222.

Malpaux, B., Robinson, J.E. \& Karsch, F.J. (1985) Is refractoriness of the ewe to short photoperiod caused by a disruption of the secretory pattern of melatonin? Biol. Reprod. 32, Suppl. 1, Abstr. 42.

Niswender, G.D., Reichert, L.E., Jr, Midgley, A.R., Jr \& Nalbandov, A.V. (1969) Radioimmunoassay for bovine and ovine luteinizing hormone. Endocrinology 84, 1166-1173.

Pittendrigh, C.S. \& Daan, S. (1976) A functional analysis of circadian pacemakers in nocturnal rodents. 1 . The stability and lability of spontaneous frequency. $J$. comp. Physiol. 106, 223-252.

Reiter, R.J. \& Follett, B.K. (1980) Seasonal Reproduction in Higher Vertebrates. S. Karger, Basel.

Robinson, J.E. \& Follett, B.K. (1982) Photoperiodism in Japanese quail: the termination of seasonal breeding by photorefractoriness. Proc. R. Soc. Lond. B. 215, 95-116.

Robinson, J.E. \& Karsch, F.J. (1984) Refractoriness to inductive daylengths terminates the breeding season of the Suffolk ewe. Biol. Reprod. 34, 656-663.

Robinson, J.E., Wayne, N.L. \& Karsch, F.J. (1985) Refractoriness to inhibitory daylengths initiates the breeding season the Suffolk ewe. Biol. Reprod. 32, 1024-1030.

Rollag, M.D. \& Niswender, G.D. (1976) Radioimmunoassay of serum concentrations of melatonin in sheep exposed to different lighting regimes. Endocrinology 98, 482-489.

Rollag, M.D., O'Callaghan, P.L. \& Niswender, G.D. (1978) Serum melatonin concentrations during different stages of the annual reproductive cycle in ewes. Biol. Reprod. 18, 279-285.

Stetson, M.H. (1985) Maternal transfer of photoperiodic information dictates the gonadal response of prepubertal Djungarian hamsters to photoperiod. Biol. Reprod. 32, Suppl I, Abstr. 270.

Watson-Whitmyre, M. (1985) Photoperiodic regulation of sensitivity to melatonin in pinealectomized golden hamsters. Biol. Reprod. 32, Suppl. 1, Abstr. 275.

Watson-Whitmyre, M. \& Stetson, M.H. (1983) Stimulation of peak melatonin release restores sensitivity to evening melatonin injections in pinealectomized hamsters. Endocrinology 112, 763-765.

Yeates, N.T.M. (1949) The breeding season of the sheep with particular reference to its modification by artificial light. J. agric. Sci., Camb. 39, 1-43.

Yellon, S.M., Bittman, E.L., Lehman, M.N., Olster, D.H., Robinson, J.E. \& Karsch, F.J. (1985) Importance of duration of nocturnal melatonin secretion in determining the reproductive response to inductive photoperiod in the ewe. Biol. Reprod. 32, 523-529. 